OPEN ACCESS

Edited by:

Jian Liu,

Curtin University, Australia

Reviewed by:

Xuefeng Zhu,

Dalian Institute of Chemical Physics

(CAS), China

Shaobin Wang,

Curtin University, Australia

*Correspondence:

Hui Peng

penghui@qibebt.ac.cn

Heqing Jiang

jianghq@qibebt.ac.cn

tThese authors have contributed equally to this work.

Specialty section

This article was submitted to Chemical Engineering,

a section of the journal

Frontiers in Chemistry

Received: 07 March 2018

Accepted: 16 July 2018

Published: 06 August 2018

Citation:

Hu T, Zhou H, Peng H and Jiang $H$

(2018) Nitrogen Production by

Efficiently Removing Oxygen From Air

Using a Perovskite Hollow-Fiber

Membrane With Porous Catalytic

Layer. Front. Chem. 6:329.

doi: 10.3389/fchem.2018.00329

\section{Nitrogen Production by Efficiently Removing Oxygen From Air Using a Perovskite Hollow-Fiber Membrane With Porous Catalytic Layer}

\author{
Tianmiao Hu ${ }^{1,2 \dagger}$, Hangyue Zhou $^{1,2 t}$, Hui Peng ${ }^{1 *}$ and Heqing Jiang ${ }^{1 *}$ \\ ${ }^{1}$ Qingdao Key Laboratory of Functional Membrane Material and Membrane Technology, Qingdao Institute of Bioenergy and \\ Bioprocess Technology, Chinese Academy of Sciences, Qingdao, China, ${ }^{2}$ University of Chinese Academy of Sciences, \\ Beijing, China
}

Nowadays, nitrogen is mainly produced from air by cryogenic separation, pressureswing adsorption (PSA) and polymeric membrane technology. In this paper, we report a perovskite membrane-based nitrogen production route, which is basically driven by methane combustion. By coupling air separation with methane combustion on the opposite sides of oxygen-permeable perovskite membrane, most of oxygen in air is efficiently removed through the perovskite membrane and then consumed by methane oxidation. A nitrogen production rate of ca. $23 \mathrm{~cm}^{3} \mathrm{~min}^{-1}$ with purity of 98-99\% was successfully achieved, and remained stable over $120 \mathrm{~h}$, with a methane conversion of $71-73 \%$ on the other side of perovskite membrane. This work demonstrates that the joint use of oxygen-permeable perovskite membrane and methane oxidation is a promising strategy for nitrogen production and inspires more research efforts in the field of gas separation.

Keywords: nitrogen production, perovskite, oxygen transport membrane, hollow-fiber, catalytic layer

\section{INTRODUCTION}

Nitrogen, which constitutes $78 \%$ by volume of air, is extensively applied in chemical industry, e.g., as purging gas for pipelines (Bernardo and Drioli, 2010; Ivanova and Lewis, 2012) or as feed gas in ammonia synthesis (Kyriakou et al., 2017). To date, commercial-scale nitrogen production mainly adopts cryogenic separation, pressure-swing adsorption (PSA) or polymeric membrane technology (Koros and Mahajan, 2000; Castle, 2002). Since developed by Linde (1903), cryogenic separation technology is widely used in large-scale air separation plants and can provide nitrogen with extremely ultra-high purity (99.9999\%) (Ivanova and Lewis, 2012). Considering the large site area, huge capital and energy costs of developing cryogenic plants, PSA or polymeric membrane separation technology has caught worldwide interests on satisfying the demands of those air separation plants with small to medium nitrogen production capacity or without requiring ultrahigh purity (Puranik et al., 2016). In membrane separation system, nitrogen/oxygen separation is driven by the gradient in concentration or partial pressure (or both) across the membrane (Gin and Noble, 2011). Under this driving force, nitrogen and oxygen are separated by polymeric membranes based on the solution diffusion mechanism (Baker and Low, 2014), which is governed by permeability and selectivity (Chong et al., 2016). However, the difference of kinetic diameters 
between oxygen (3.46 $\AA$ ) and nitrogen $(3.64 \AA)$ is too small, and thus it is usually difficult to obtain a very high permselectivity using the polymeric membranes (Dong et al., 2013). Furthermore, polymeric membranes for gas separation are also restricted by their poor chemical and thermal stability (Robeson, 1999; Park et al., 2010).

In past decades, dense perovskite membranes, which possess mixed oxygen ionic and electronic conductivity, attract growing attentions owing to theoretically $100 \%$ permselectivity for oxygen in air separation (Feldhoff et al., 2007). At high temperature, oxygen molecules are converted to oxygen ions over perovskite membrane surface and then diffuse through membrane driven by the oxygen partial pressure gradient. As a result, oxygen can be separated from air by using perovskite type oxide membranes. Many relevant researches have been done to achieve the oxygen production via perovskite oxygen-permeable membranes (Shao et al., 2000; Jin et al., 2001; Luo et al., 2010), and a satisfactory oxygen purity could be achieved over $99.4 \%$ (Zhu et al., 2009; Liang et al., 2010).

In fact, the concentration of nitrogen will be significantly increased when oxygen in the stream is removed to the other side via perovskite oxygen-permeable membranes. Thus, it is expected that the production of nitrogen with purity of above $97 \%$ can be achieved if most of the oxygen in the fed air is efficiently removed. Our recent study has indicated the feasibility of producing nitrogen using $\mathrm{Ce}_{0.9} \mathrm{Pr}_{0.1} \mathrm{O}_{2-\delta}-\mathrm{Pr}_{0.6} \mathrm{Sr}_{0.4} \mathrm{FeO}_{3-\delta}$ (CPO-PSFO) disk-shaped oxygen-permeable membrane. To get a higher nitrogen production rate, one can choose the membrane that shows higher oxygen permeability. In addition, the oxygen permeation flux can be further improved if the permeated oxygen can be fast consumed on the permeate side of perovskite membrane. For example, Jiang et al. (2010b) reported that, the oxygen permeation flux of a perovskite $\mathrm{BaCo}_{\mathrm{x}} \mathrm{Fe}_{\mathrm{y}} \mathrm{Zr}_{1-\mathrm{x}-\mathrm{y}} \mathrm{O}_{3-\delta}$ (BCFZ) hollow-fiber membrane increased from 3.3 to $8 \mathrm{~cm}^{3}$ $\mathrm{min}^{-1} \mathrm{~cm}^{-2}$ when methane was fed on shell side at $875^{\circ} \mathrm{C}$. Lobera et al. (2012) further observed that when dilute methane was used as sweep gas in a perovskite $\mathrm{Ba}_{0.5} \mathrm{Sr}_{0.5} \mathrm{Co}_{0.8} \mathrm{Fe}_{0.2} \mathrm{O}_{3-\delta}$ (BSCF) membrane reactor, the logarithm of oxygen partial pressure gradient increased from 1.16 to 4.02 , resulting in a 2.5 fold increase of oxygen permeation flux. Inspired by promoted oxygen removal performance, it is feasible to produce high purity nitrogen driven by an oxygen consumption reaction in perovskite membrane reactor. Compared with disk-shaped membranes, the hollow-fiber membrane, produced via phase inversion process, can provide higher oxygen permeation flux and larger membrane area per unit packing volume when packed into a membrane module. In this work, we combined air separation with methane combustion in a perovskite BCFZ hollow-fiber membrane reactor for nitrogen production, which has been previously used for the production of oxygen-enriched air (Hamel et al., 2006; Liang et al., 2010) and the partial oxidation or dehydrogenation of light hydrocarbons (Jiang et al., 2009, 2010a). The influences of porous catalytic layer, methane concentration and operation temperatures on nitrogen production were investigated, and the feasibility of producing nitrogen with the purity of $98-99 \%$ have been demonstrated by using perovskite BCFZ hollow-fiber membrane.

\section{EXPERIMENTAL SECTION}

\section{Fabrication of Perovskite Membranes With Porous Catalytic Layer}

Perovskite BCFZ powders were prepared through the one-pot citric acid-ethylenediaminetetraacetic acid (EDTA) complexing process, as described in detail elsewhere (Dong et al., 2010; Liang et al., 2013). The stoichiometric amounts of metal nitrates, citric acid and EDTA (the molar ratios of EDTA/citric acid/metal cations $=1: 1.5: 1)$ were dissolved in deionized water. And the $\mathrm{pH}$ value was adjusted to $8-9$ using aqueous ammonia. After being stirred overnight, the homogenized precursor solution was heated to remove water. Then, the resultant dark gel was burnt on a hot plate and further calcined at $950^{\circ} \mathrm{C}$ for $5 \mathrm{~h}$ in muffle oven.

Dense BCFZ hollow-fiber membrane used in this work was obtained from Fraunhofer Institute for Interfacial Engineering and Biotechnology (IGB). BCFZ slurry (a mixture of BCFZ powders and deionized water) was brushed on the central part

\section{A}

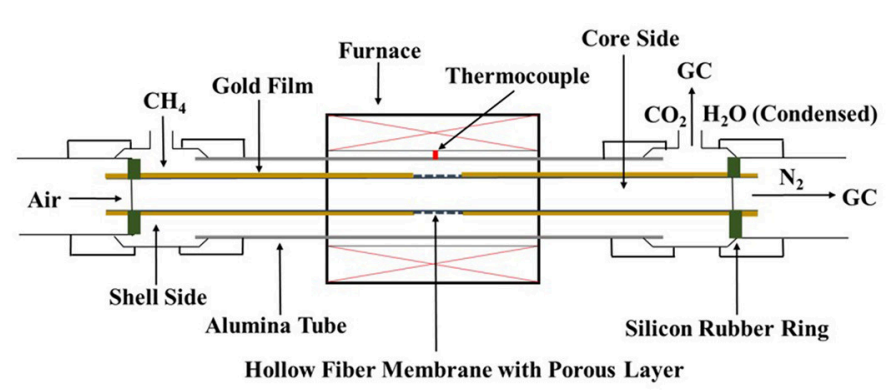

B

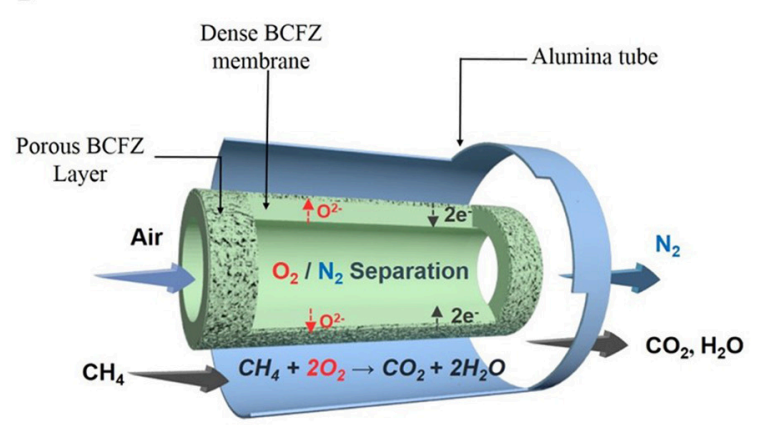

FIGURE 1 | Schematic diagram of the BCFZ hollow-fiber membrane reactor (A) used in this work, and the scheme of nitrogen production with in situ removal of oxygen via perovskite hollow-fiber membrane (B). 

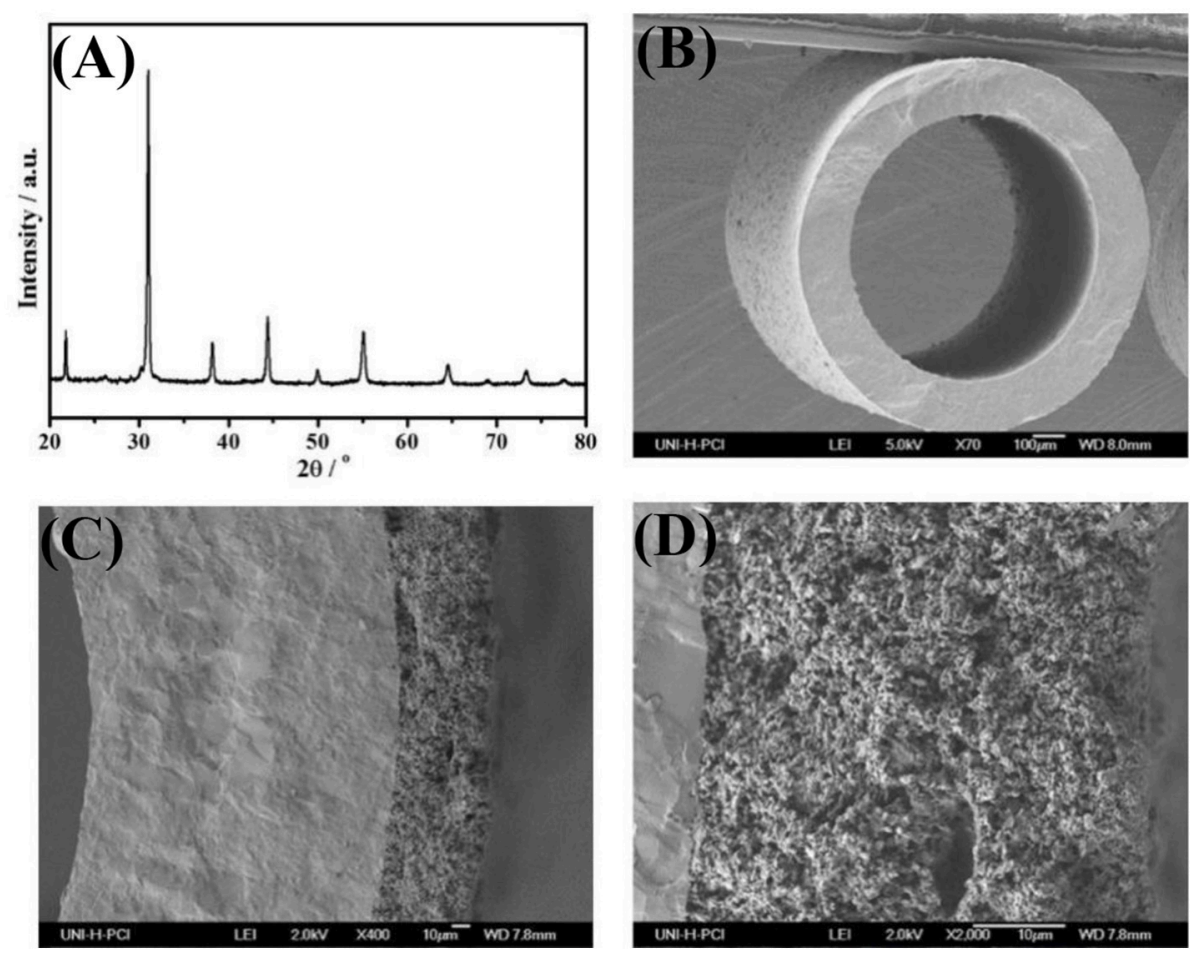

FIGURE 2 | The XRD-patterns of fresh BCFZ powders (A) after being calcined at $950^{\circ} \mathrm{C}$ for $5 \mathrm{~h}$, cross-section micrographs of the uncoated (B) and coated BCFZ hollow-fiber membrane (C,D).
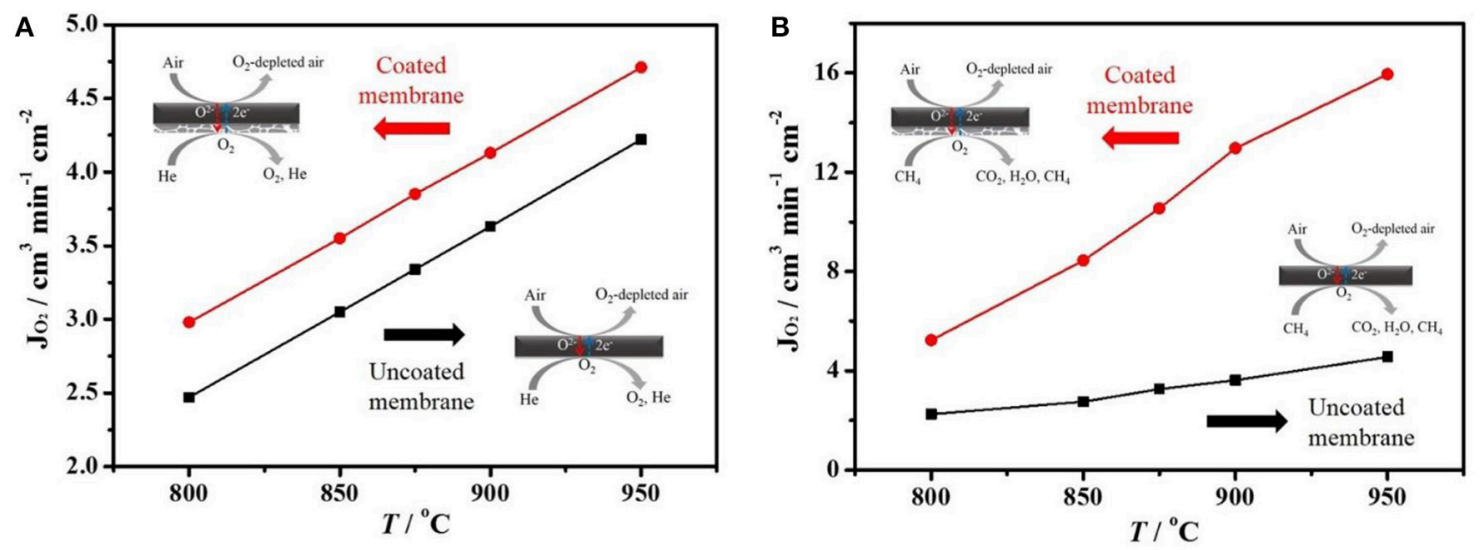

FIGURE 3 | Oxygen permeation fluxes $\left(\mathrm{J}_{2}\right)$ of a coated or uncoated BCFZ hollow-fiber membrane as a function of temperature. Membrane area: $0.8 \mathrm{~cm}{ }^{2}$. (A) Core side: $F_{\text {Air }}=150 \mathrm{~cm}^{3} \mathrm{~min}^{-1}$. Shell side: $F_{\mathrm{He}}=49 \mathrm{~cm}^{3} \mathrm{~min}^{-1}, F_{\mathrm{Ne}}=1 \mathrm{~cm}^{3} \mathrm{~min}^{-1}$ (for calculating $\mathrm{J}_{2}$ ). (B) Core side: $F_{\mathrm{Air}}=149 \mathrm{~cm}^{3} \mathrm{~min}^{-1}, F_{\mathrm{Ne}}=1 \mathrm{~cm}^{3} \mathrm{~min}^{-1}$ (for calculating $J_{\mathrm{O}_{2}}$ ). Shell side: $F_{\mathrm{He}}=40 \mathrm{~cm}^{3} \mathrm{~min}^{-1}, F_{\mathrm{CH}_{4}}=10 \mathrm{~cm}^{3} \mathrm{~min}^{-1}$.

of membrane outside surface. Then the coated membrane was heated at $1050^{\circ} \mathrm{C}$ for $1 \mathrm{~h}$ to make porous layer. For ensuring isothermal condition during performance tests, BCFZ hollowfiber membrane (except porous layer part) was coated by $\mathrm{Au}$ paste, and then treated at $950^{\circ} \mathrm{C}$ to form a dense oxygenimpermeable film.

\section{Characterization of Materials}

The crystal structure of fresh BCFZ powders was identified by X-ray diffraction (XRD, Bruker D8 Advance) equipped with a monochromator using $\mathrm{Cu} \mathrm{K} \alpha$ radiation at room temperature. Experimental diffraction patterns were collected in a $2 \theta$ range of $20-80^{\circ}$. The outside surface and cross-section morphology 

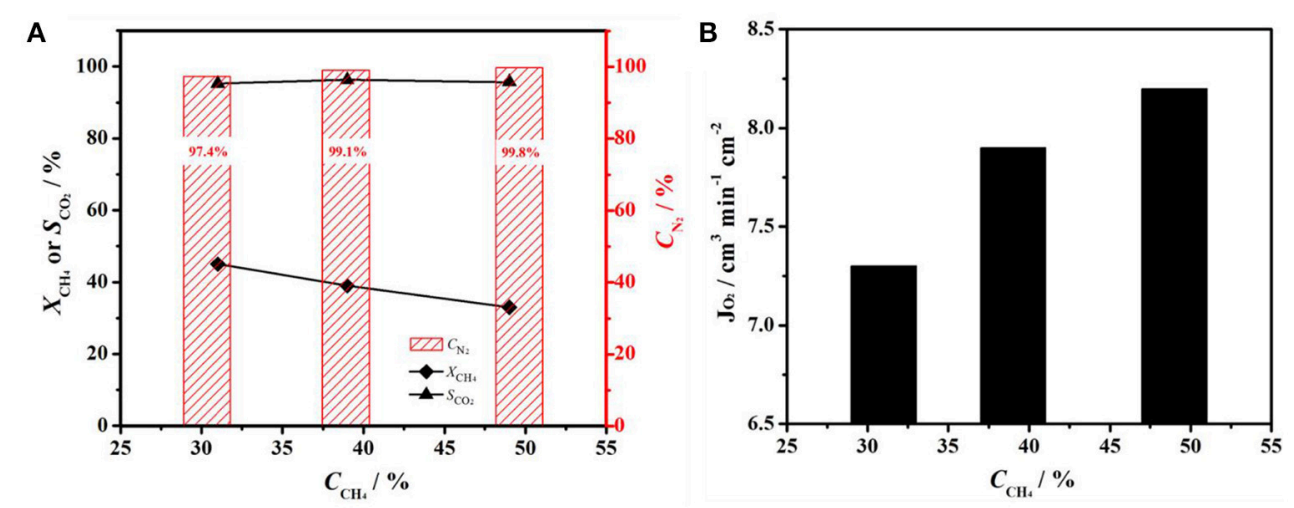

FIGURE 4 | (A) Nitrogen purity $\left(\mathrm{C}_{\mathrm{N}_{2}}\right), \mathrm{CH}_{4}$ conversion $\left(\mathrm{X}_{\mathrm{CH}_{4}}\right)$ and $\mathrm{CO}_{2}$ selectivity $\left(\mathrm{S}_{\mathrm{CO}_{2}}\right)$, and $(\mathbf{B})$ oxygen fluxes $\left(\mathrm{J}_{2}\right)$ as a function of methane concentration on a BCFZ hollow-fiber membrane with porous layer at $875^{\circ} \mathrm{C}$. Membrane area: $1.1 \mathrm{~cm}^{2}$. Core side: $F_{\text {Air }}=48 \mathrm{~cm}^{3} \mathrm{~min}^{-1}$. Shell side: $F_{\mathrm{CH}_{4}}+F_{\mathrm{He}}=30 \mathrm{~cm}^{3} \mathrm{~min}^{-1}$.
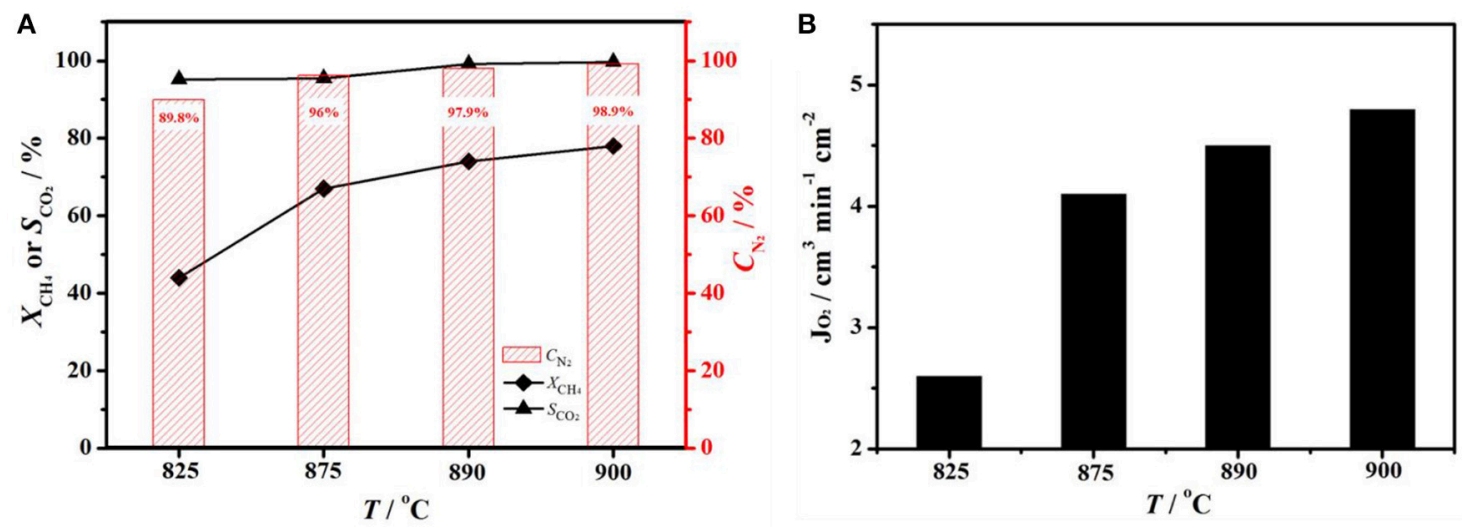

FIGURE 5 | (A) Nitrogen purity $\left(C_{N_{2}}\right), C_{4}$ conversion $\left(X_{\mathrm{CH}_{4}}\right)$ and $\mathrm{CO}_{2}$ selectivity $\left(\mathrm{S}_{\mathrm{CO}_{2}}\right)$, (B) oxygen fluxes $\left(\mathrm{J}_{2}\right)$ as a function of temperature on a BCFZ hollow-fiber membrane with porous layer. Membrane area: $1.1 \mathrm{~cm}^{2}$. Core side: $F_{\text {Air }}=29 \mathrm{~cm}^{3} \mathrm{~min}^{-1}$. Shell side: $F_{\mathrm{CH}_{4}}=3.5 \mathrm{~cm}^{3} \mathrm{~min}^{-1}, F_{\mathrm{He}}=7 \mathrm{~cm}^{3} \mathrm{~min}^{-1}$.

of fresh BCFZ uncoated hollow-fiber membrane and the one with porous layer were observed by using a JEOL JSM-6700F field emission scanning electron microscope (SEM); and the morphology of hollow-fiber membrane with porous layer after measurements and $120 \mathrm{~h}$ operation was studied by using a Hitachi S-4800 SEM.

\section{Nitrogen Production Tests}

Nitrogen production was carried out in a lab-made hightemperature device, as shown in Figure 1A. Outside the furnace, silicon-rubber rings were used to seal the two ends of BCFZ hollow-fiber membrane. And the porous layer part was located in the middle of the furnace to make it isothermal. The sealing performance of membrane reactor was checked before nitrogen production tests. The leakages of oxygen were no more than $1 \%$, which demonstrated a good sealing performance. Then, synthetic air was fed into core side of membrane reactor, diluted methane was fed simultaneously into shell side. The flow rates of each gas were controlled by gas mass-flow controllers. The concentrations of each gas at the exit of BCFZ hollow-fiber membrane reactor was analyzed by an on-line gas chromatograph.

The nitrogen purity $\left(C_{\mathrm{N}_{2}}\right)$, production rate of nitrogen $\left(P_{\mathrm{N}_{2}}\right)$, oxygen permeation flux $\left(\mathrm{O}_{2}\right)$, methane conversion $\left(X_{\mathrm{CH}_{4}}\right)$ and $\mathrm{CO}_{2}$ selectivity $\left(\mathrm{S}_{\mathrm{CO}_{2}}\right)$ were calculated according to following equations:

$$
\begin{aligned}
C_{\mathrm{N}_{2}} & =\left(1-\frac{F_{\mathrm{O}_{2}, \text { out }}}{F_{\text {total,out }}}\right) \times 100 \% \\
P_{\mathrm{N}_{2}} & =F_{\text {total,out }} \times C_{\mathrm{N}_{2}} \\
J_{\mathrm{O}_{2}} & =\frac{F_{\mathrm{O}_{2} \text {,in }}-F_{\mathrm{O}_{2}, \text { out }}}{S} \\
X_{\mathrm{CH}_{4}} & =\left(1-\frac{F_{\mathrm{CH}_{4}, \text { out }}}{F_{\mathrm{CH}_{4}, \text { in }}}\right) \times 100 \% \\
S_{\mathrm{CO}_{2}} & =\frac{F_{\mathrm{CO}_{2}, \text { out }}}{F_{\mathrm{CH}_{4}, \text { in }}-F_{\mathrm{CH}_{4}, \text { out }}} \times 100 \%
\end{aligned}
$$

Where $F_{\mathrm{i}}$ is the flow rate of gas $i, S$ is the effective area of hollow-fiber membrane. 

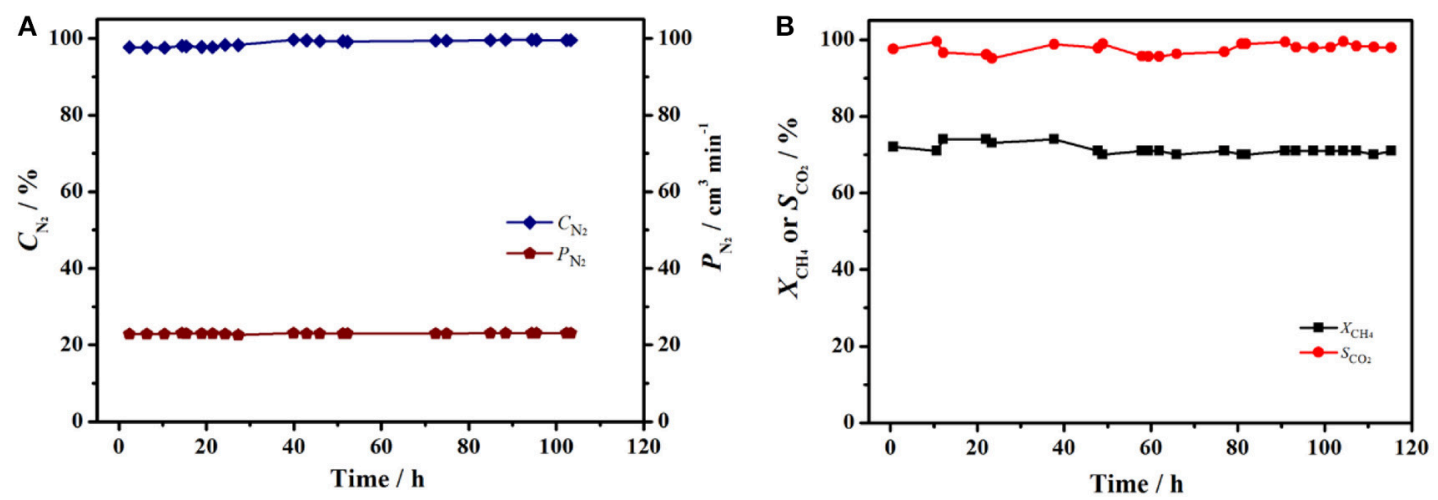

FIGURE 6 | Long time stability test of BCFZ hollow-fiber membrane with porous layer at $890^{\circ} \mathrm{C}$. (A) Production rate of nitrogen $\left(P_{\mathrm{N}_{2}}\right)$ and nitrogen purity $\left(C_{\mathrm{N}_{2}}\right)$,(B) $\mathrm{CH}_{4}$ conversion $\left(X_{\mathrm{CH}_{4}}\right)$ and $\mathrm{CO}_{2}$ selectivity $\left(S_{\mathrm{CO}_{2}}\right)$. Membrane area: $1.1 \mathrm{~cm}^{2}$. Core side: $F_{\text {Air }}=29 \mathrm{~cm}^{3} \mathrm{~min}^{-1}$. Shell side: $F_{\mathrm{CH}_{4}}=3.5 \mathrm{~cm}^{3} \mathrm{~min}^{-1}, F_{\mathrm{N}_{2}}=7 \mathrm{~cm}^{3} \mathrm{~min}^{-1}$.
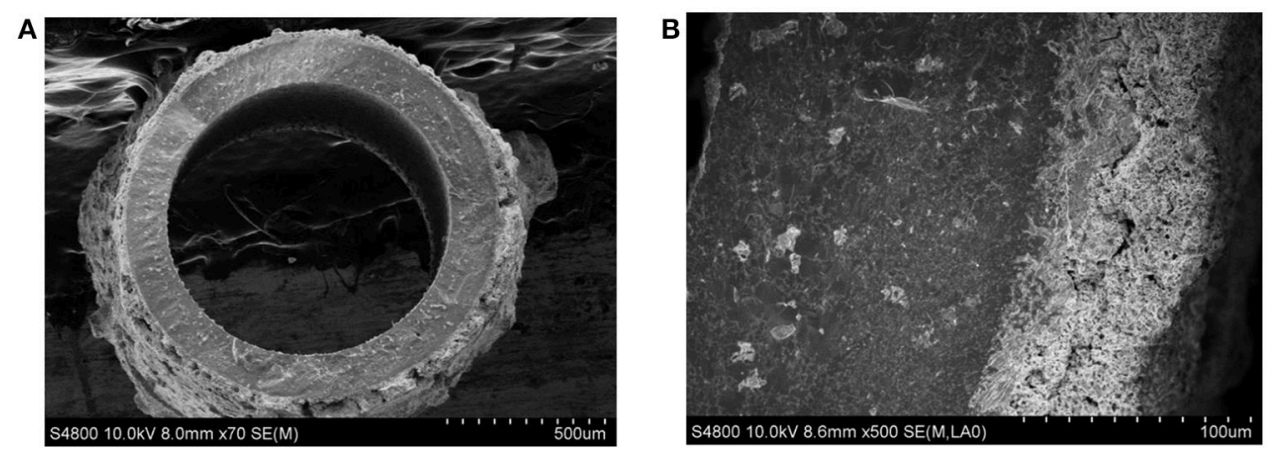

FIGURE 7 | The SEM images of the BCFZ hollow-fiber membrane with porous layer after $120 \mathrm{~h}$ operation. (A) Cross-section micrograph and (B) magnified one.

\section{RESULTS AND DISCUSSION}

The XRD patterns of as-obtained BCFZ powder (calcined under air at $950^{\circ} \mathrm{C}$ for $5 \mathrm{~h}$ ) is presented on Figure 2A. It can be found that BCFZ material possesses a typical perovskite structure, which corresponds with the observation of Wang et al. (2005). It was reported that BCFZ oxide remained its perovskite structure during the temperature increasing from 30 to $1000^{\circ} \mathrm{C}$, with a heating rate of $5^{\circ} \mathrm{C} / \mathrm{min}$ (Wang et al., 2005). Figures 2B-D show the cross-section micrographs of BCFZ fresh hollow-fiber with / without BCFZ porous layer. Unlike hollow-fibers with fingerlike straight pores used in other works (Wang et al., 2009; Wu et al., 2013), it can be seen from Figure 2B the BCFZ hollow-fiber membrane is dense and no crack can be observed in the bulk of the membrane. This hollow-fiber membrane without fingerlike pores could bring higher mechanical strength. Moreover, the outer diameter of the fiber is $800-900 \mu \mathrm{m}$ and inner diameter is $500-600 \mu \mathrm{m}$. To efficiently catalyze the methane oxidation over membrane surface, in our work, a porous BCFZ layer is deposited on the outside surface of BCFZ hollow-fiber membrane followed by treating at $1050^{\circ} \mathrm{C}$ for $1 \mathrm{~h}$. From Figure 2C, it can be seen that $\mathrm{BCFZ}$ porous layer is well deposited on the outside surface of dense membrane. In addition, unlike the dense membrane, the heat-treated outside BCFZ layer is still porous. The magnified image, as shown in Figure 2D, indicates that the connected BCFZ particles construct a porous three-dimensional network.

The oxygen permeation fluxes of coated/uncoated BCFZ hollow-fiber membrane were measured in a high temperature permeation cell (see Figure 1) using inert He or diluted methane as sweep gas. As shown in Figure 3A, the oxygen permeation fluxes increased with temperature raising for the coated and uncoated membranes. The increase of oxygen permeation flux should result from the faster surface exchange rate and the improved diffusion kinetics of oxygen ion in the bulk part of perovskite membrane with increasing operation temperature. Moreover, it was noticed from Figure 3A that the oxygen permeation fluxes of the coated BCFZ hollow-fiber membrane is slightly higher than that of uncoated membranes when using $\mathrm{He}$ as the sweep gas, and an oxygen permeation flux of ca. $4.7 \mathrm{~cm}^{3}$ $\mathrm{cm}^{-2} \mathrm{~min}^{-1}$ was obtained at $950^{\circ} \mathrm{C}$. The oxygen permeation flux of BCFZ hollow-fiber membrane is limited by surface exchange rate and bulk diffusion rate of oxygen ions based on our previous study (Jiang et al., 2010b). After depositing a BCFZ porous layer on the outside surface of BCFZ hollow-fiber membrane, there are more active sites on the permeate side (shell side) for the association of oxygen ions to form molecular oxygen, which is 
followed by desorption. This results in a slightly higher surface exchange rate. Furthermore, when diluted methane (instead of inert $\mathrm{He}$ ) was sent to the permeate side, the porous layer can well catalyze the combustion of methane $\left(\mathrm{CH} 4+4 \mathrm{O}^{2-} \rightarrow \mathrm{CO}_{2}+\right.$ $\left.2 \mathrm{H}_{2} \mathrm{O}+8 \mathrm{e}^{-}\right)$. In this case, the permeated oxygen can be reacted quickly by combustion, leading to a larger gradient of oxygen partial pressure across the membrane, thus a higher oxygen permeation flux can be expected. Figure $3 \mathbf{B}$ presents the oxygen permeation fluxes of the uncoated and coated BCFZ hollow-fiber membranes at different temperatures feeding diluted methane on the permeate side. Compared with the uncoated BCFZ membrane, oxygen permeation flux increased from 4.6 to 15.9 $\mathrm{cm}^{3} \mathrm{~min}^{-1} \mathrm{~cm}^{-2}$ at $950^{\circ} \mathrm{C}$ after being coated with a porous BCFZ layer.

From the above results, it can be demonstrated that oxygen permeation fluxes are significantly enhanced by coating BCFZ hollow-fiber membrane with a porous BCFZ layer. Thus, such BCFZ hollow-fiber membrane with a porous catalytic layer was employed to produce nitrogen by optimizing the operation conditions. In BCFZ membrane reactor, oxygen molecules from air on core side are removed as oxygen ions $\left(\mathrm{O}^{2-}\right)$ through membrane to shell side, where they are consumed quickly by methane combustion, as illustrated in Figure 1B. During this process, oxygen can be continuously removed from air, which leads to a gradual increase on the purity of nitrogen. Thus, methane concentration on shell side plays an important role on influencing nitrogen purity on core side. Figure 4 shows the effect of methane concentration on the performance of the coated BCFZ membrane reactor. With methane concentration on shell side increasing from 31 to $49 \%$, it was found that the nitrogen purity of outlet gas on core side increased from 97.4 to $99.8 \%$ according to Figure 4A. This purity meets requirements of many application fields in chemical industry, such as shielding gas or purging gas. Attributed to methane concentration increasing, oxygen on shell side would be consumed faster. Thus, the residual oxygen partial pressure on the shell side would decrease, which leads to a higher oxygen permeation flux. In our work, oxygen permeation flux increased from 7.3 to $8.2 \mathrm{~cm}^{3} \mathrm{~min}^{-1} \mathrm{~cm}^{-2}$ as methane concentration increasing from 31 to $49 \%$, as shown in Figure 4B. Therefore, higher nitrogen purity was achieved with increasing methane concentration on the permeate side. Accordingly, the methane conversion decreased significantly from 45 to $33 \%$ upon increasing methane concentration from 31 to $49 \%$ (Figure 4A). Compared with the increment of methane, the oxygen supply was not enough for the total conversion of methane although oxygen permeation rate increased from 7.3 to $8.2 \mathrm{~cm}^{3} \mathrm{~min}^{-1} \mathrm{~cm}^{-2}$, leading to a lower methane conversion. It is noticed that the carbon dioxide selectivity remained $95 \%$ in all cases, which indicated the Co-based BCFZ oxides prefer to catalyze the total oxidation of methane rather than the partial oxidation to $\mathrm{CO}$.

In order to achieve nitrogen production with a higher methane conversion on the other side of membrane, one can increase the operation temperatures. The influence of operation temperature on performance of BCFZ membrane reactor was shown in Figure 5. When temperature was $825^{\circ} \mathrm{C}$, nitrogen purity and methane conversion was 89.8 and $44 \%$, respectively
(Figure 5A). With temperature raising, both nitrogen purity and methane conversion increased significantly. When temperature reached $900^{\circ} \mathrm{C}$, nitrogen purity of $98.9 \%$ and methane conversion of $78 \%$ was obtained. Based on Wagner equation (Jiang et al., 2008; Chen et al., 2014), oxygen permeation rate is promoted by increasing operation temperature. Thus, more oxygen $\left(J_{\mathrm{O}_{2}}\right.$ increased from 2.6 to $4.8 \mathrm{~cm}^{3} \mathrm{~min}^{-1} \mathrm{~cm}^{-2}$, as shown in Figure 5B) was removed from core side to shell side and consumed by methane oxidation there. Owing to the higher oxygen permeation flux, both nitrogen purity on core side and methane conversion on shell side increased, and carbon dioxide selectivity almost kept constant.

The stable operation to produce nitrogen from air using perovskite BCFZ hollow-fiber membrane with a porous catalytic layer was conducted. During the test period of $120 \mathrm{~h}$, nitrogen was produced at a rate of ca. $23 \mathrm{~cm}^{3} \mathrm{~min}^{-1}$ with a purity of 98-99\% on core side (Figure 6A), and a methane conversion of $71-73 \%$ with a carbon dioxide selectivity of above $95 \%$ were also achieved (Figure 6B) on shell side at $890^{\circ} \mathrm{C}$. The nitrogen production from air using ceramic catalytic membrane driven by methane oxidation seems promising based on our study. In addition, as shown in Figure 7A, the porous layer is still well coated on outside surface of BCFZ hollow-fiber membrane after $120 \mathrm{~h}$ operation, and according to magnified image (Figure 7B), the surface layer is still porous, which supports the stable performance.

\section{CONCLUSIONS}

In summary, we demonstrated the nitrogen production using a perovskite oxygen-permeable membrane with a porous catalytic layer, in which air separation was coupled with methane combustion on the opposite sides of membrane reactor. Based on in-situ and fast removal of oxygen in air by using the oxygenpermeable membrane, nitrogen was produced at a rate of ca. 23 $\mathrm{cm}^{3} \mathrm{~min}^{-1}$ with a purity of $98-99 \%$ on core side of BCFZ hollowfiber membrane. On shell side, a methane conversion of $71-73 \%$ and a carbon dioxide selectivity of above $95 \%$ were also achieved at $890^{\circ} \mathrm{C}$ and it can be steadily operated for over $120 \mathrm{~h}$. The joint use of oxygen-permeable membrane and methane combustion seems a promising and efficient strategy for nitrogen production. This technology seems economically attractive especially when the low quality of methane such as the flare gas in the offshore platform is used to drive the membrane-based separation. This will also inspire more research efforts in the field of gas separation using perovskite catalytic membrane.

\section{AUTHOR CONTRIBUTIONS}

$\mathrm{HP}$ and HJ conceived and designed the experiments; TH and HZ conducted the experiments and analyzed the data; TH wrote the draft, and HP and HJ improved it.

\section{FUNDING}

This work was financially supported by the National Natural Science Foundation of China $(21471156,51761145107)$. 


\section{ACKNOWLEDGMENTS}

We thank Dr. T. Schiestel from Fraunhofer Institute of Interfacial Engineering and Biotechnology for providing

\section{REFERENCES}

Baker, R. W., and Low, B. T. (2014). Gas separation membrane materials: a perspective. Macromolecules 47, 6999-7013. doi: 10.1021/ma501488s

Bernardo, P., and Drioli, E. (2010). Membrane gas separation progresses for process intensification strategy in the petrochemical industry. Petrol. Chem. 50, 271-282. doi: 10.1134/S0965544110040043

Castle, W. F. (2002). Air separation and liquefaction: recent developments and prospects for the beginning of the new millennium. Intl. J. Refrigerat. 25, 158-172. doi: 10.1016/S0140-7007(01)00003-2

Chen, W., Chen, C. S., Bouwmeester, H. J. M., Nijmeijer, A., and Winnubst, L. (2014). Oxygen-selective membranes integrated with oxy-fuel combustion. J. Membr. Sci. 463, 166-172. doi: 10.1016/j.memsci.2014.03.063

Chong, K. C., Lai, S. O., Thiam, H. S., Teoh, H. C., and Heng, S. L. (2016). Recent progress of oxygen/nitrogen separation using membrane technology. J. Eng. Sci. Technol. 11, 1016-1030.

Dong, G., Li, H., and Chen, V. (2013). Challenges and opportunities for mixedmatrix membranes for gas separation. J. Mater. Chem. A 1, 4610- 4630. doi: $10.1039 / \mathrm{c} 3 \mathrm{ta} 00927 \mathrm{k}$

Dong, X. L., Jin, W. Q., and Xu, N. P. (2010). Reduction-tolerant oxygenpermeable perovskite-type oxide $\mathrm{Sr}_{0.7} \mathrm{Ba}_{0.3} \mathrm{Fe}_{0.9} \mathrm{Mo}_{0.1} \mathrm{O}_{3-\delta}$. Chem. Mater. 22, 3610-3618. doi: $10.1021 / \mathrm{cm} 903862 y$

Feldhoff, A., Martynczuk, J., and Wang, H. H. (2007). Advanced $\mathrm{Ba}_{0.5} \mathrm{Sr}_{0.5} \mathrm{Zn}_{0.2} \mathrm{Fe}_{0.8} \mathrm{O}_{3-\delta}$ perovskite-type ceramics as oxygen selective membranes: evaluation of the synthetic process. Prog. Solid State Chem. 35, 339-353. doi: 10.1016/j.progsolidstchem.2007.01.007

Gin, D. L., and Noble, R. D. (2011). Chemistry. Designing the next generation of chemical separation membranes. Science 332, 674-676. doi: 10.1126/science.1203771

Hamel, C., Seidel-Morgenstern, A., Schiestel, T., Werth, S., Wang, H. H., Tablet, C. T., et al. (2006). Experimental and modeling study of the $\mathrm{O}_{2}$-enrichment by perovskite fibers. AIChE J. 52, 3118-3125. doi: 10.1002/aic.10934

Ivanova, S., and Lewis, R. (2012). Producing nitrogen via pressure swing. Chem. Eng. Prog. 108, 38-42.

Jiang, H., Cao, Z., Schirrmeister, S., Schiestel, T., and Caro, J. (2010a). A coupling strategy to produce hydrogen and ethylene in a membrane reactor. Angew. Chem. Intl. Ed. Engl. 49, 5656-5660. doi: 10.1002/anie.201000664

Jiang, H. Q., Liang, F. Y., Czuprat, O., Efimov, K., Feldhoff, A., Schirrmeister, S., et al. (2010b). Hydrogen production by water dissociation in surfacemodified $\mathrm{BaCo}_{\mathrm{x}} \mathrm{Fe}_{\mathrm{y}} \mathrm{Zr}_{1-} \mathrm{x}_{-} \mathrm{y}_{3-} \mathrm{O}_{3}$ hollow-fiber membrane reactor with improved oxygen permeation. Chem. A Eur. J. 16, 7898-7903. doi: 10.1002/chem.200902494

Jiang, H., Wang, H., Liang, F., Werth, S., Schiestel, T., and Caro, J. (2009). Direct decomposition of nitrous oxide to nitrogen by in situ oxygen removal with a perovskite membrane. Angew. Chem. Int. Ed. Engl. 48, 2983-2986. doi: 10.1002/anie.200804582

Jiang, H., Wang, H., Werth, S., Schiestel, T., and Caro, J. (2008). Simultaneous production of hydrogen and synthesis gas by combining water splitting with partial oxidation of methane in a hollow-fiber membrane reactor. Angew. Chem. Intl. Ed. Engl. 47, 9341-9344. doi: 10.1002/anie.200803899

Jin, W. Q., Li, S. G., Huang, P., Xu, N. P., and Shi, J. (2001). Preparation of an asymmetric perovskite-type membrane and its oxygen permeability. J. Membr. Sci. 185, 237-243. doi: 10.1016/S0376-7388(00)00650-5

Koros, W. J., and Mahajan, R. (2000). Pushing the limits on possibilities for large scale gas separation: which strategies? J. Membr. Sci. 175, 181-196. doi: 10.1016/S0376-7388(00)00418-X

Kyriakou, V., Garagounis, I., Vasileiou, E., Vourros, A., and Stoukides, M. (2017). Progress in the electrochemical synthesis of ammonia. Catal. Today 286, 2-13. doi: 10.1016/j.cattod.2016.06.014 the hollow fiber membrane, and Mr. Xing and Prof. Caro from Leibniz University of Hannover for the help with measurements and fruitful discussions.
Liang, F. Y., Jiang, H. Q., Schiestel, T., and Caro, J. (2010). High-purity oxygen production from air using perovskite hollow fiber membranes. Ind. Eng.Chem. Res. 49, 9377-9384. doi: 10.1021/ie101311g

Liang, F. Y., Partovi, K., Jiang, H. Q., Luo, H. X., and Caro, J. (2013). B-site La-doped $\mathrm{BaFe}_{0.95-\mathrm{x}} \mathrm{La}_{\mathrm{x}} \mathrm{Zr}_{0.05} \mathrm{O}_{3-\delta}$ perovskite-type membranes for oxygen separation. J. Mater. Chem. A 1, 746-751. doi: 10.1039/C2TA00 $377 \mathrm{E}$

Linde, C. (1903). Process of Producing Low Temperatures, the Liquefaction of Gases, and the Separation of the Constituents of Gaseous Mixtures. U.S. Patent No. 727, 650. Washington, DC: U.S. Patent and Trademark Office.

Lobera, M. P., Escolastico, S., Garcia-Fayos, J., and Serra, J. M. (2012). Ethylene production by ODHE in catalytically modified $\mathrm{Ba}_{0.5} \mathrm{Sr}_{0.5} \mathrm{Co}_{0.8} \mathrm{Fe}_{0.2} \mathrm{O}_{3-\delta}$ membrane reactors. ChemSusChem 5, 1587-1596. doi: 10.1002/cssc.20110 0747

Luo, H. X., Wei, Y. Y., Jiang, H. Q., Yuan, W. H., Lv, Y. X., Caro, J., et al. (2010). Performance of a ceramic membrane reactor with high oxygen flux Tacontaining perovskite for the partial oxidation of methane to syngas. J. Membr. Sci. 350, 154-160. doi: 10.1016/j.memsci.2009.12.023

Park, H. B., Han, S. H., Jung, C. H., Lee, Y. M., and Hill, A. J. (2010). Thermally rearranged (TR) polymer membranes for $\mathrm{CO}_{2}$ separation. J. Membr. Sci. 359, 11-24. doi: 10.1016/j.memsci.2009.09.037

Puranik, Y., Kilinç, M., Sahinidis, N. V., Li, T., Gopalakrishnan, A., Besancon, B. et al. (2016). Global optimization of an industrial gas network operation. AIChE J. 62, 3215-3224. doi: 10.1002/aic.15344

Robeson, L. M. (1999). Polymer membranes for gas separation. Curr. Opin. Solid State Mater. Sci. 4, 549-552. doi: 10.1016/S1359-0286(00) 00014-0

Shao, Z. P., Yang, W. S., Cong, Y., Dong, H., Tong, J. H., and Xiong, G. X. (2000). Investigation of the permeation behavior and stability of a $\mathrm{Ba}_{0.5} \mathrm{Sr}_{0.5} \mathrm{Co}_{0.8} \mathrm{Fe}_{0.2} \mathrm{O}_{3-\delta}$ oxygen membrane. J. Membr. Sci. 172, 177-188. doi: 10.1016/S0376-7388(00)00337-9

Wang, H. H., Tablet, C., Yang, W. S., and Caro, J. (2005). In situ high temperature $\mathrm{X}$-ray diffraction studies of mixed ionic and electronic conducting perovskitetype membranes. Mater. Lett. 59, 3750-3755. doi: 10.1016/j.matlet.2005. 06.067

Wang, Z., Yang, N., Meng, B., Tan, X., and Li, K. (2009). Preparation and oxygen permeation properties of highly asymmetric $\mathrm{La}_{0.6} \mathrm{Sr}_{0.4} \mathrm{Co}_{0.2} \mathrm{Fe}_{0.8} \mathrm{O}_{3--\delta}$ perovskite hollow-fiber membranes. Ind. Eng. Chem. Res. 48, 510-516. doi: 10.1021/ie8010462

Wu, Z., Faiz, R., Li, T., Kingsbury, B. F. K., and Li, K. (2013). A controlled sintering process for more permeable ceramic hollow fibre membranes. J. Membr. Sci. 446, 286-293. doi: 10.1016/j.memsci.2013.05.040

Zhu, X. F., Sun, S. M., Cong, Y., and Yang, W. S. (2009). Operation of perovskite membrane under vacuum and elevated pressures for high-purity oxygen production. J. Membr. Sci. 345, 47-52. doi: 10.1016/j.memsci.2009.08.020

Conflict of Interest Statement: The authors declare that the research was conducted in the absence of any commercial or financial relationships that could be construed as a potential conflict of interest.

The reviewer SW and handling Editor declared their shared affiliation.

Copyright (c) $2018 \mathrm{Hu}$, Zhou, Peng and Jiang. This is an open-access article distributed under the terms of the Creative Commons Attribution License (CC BY). The use, distribution or reproduction in other forums is permitted, provided the original author(s) and the copyright owner(s) are credited and that the original publication in this journal is cited, in accordance with accepted academic practice. No use, distribution or reproduction is permitted which does not comply with these terms. 